\title{
Oral Health Messiers: Diabetes Mellitus Relevance
}

\author{
Rahnuma Ahmad (iD) \\ Mainul Haque (iD ${ }^{2}$ \\ 'Department of Physiology, Medical \\ College for Women and Hospital, Dhaka, \\ Bangladesh; ${ }^{2}$ The Unit of Pharmacology, \\ Faculty of Medicine and Defence Health, \\ Universiti Pertahanan Nasional Malaysia \\ (National Defence University of \\ Malaysia), Kuala Lumpur, 57000, Malaysia
}

Correspondence: Mainul Haque The Unit of Pharmacology, Faculty of Medicine and Defence Health, Universiti Pertahanan Nasional Malaysia (National Defence University of Malaysia), Kem Perdana Sungai Besi, Kuala Lumpur, 57000, Malaysia

Email runurono@gmail.com

\begin{abstract}
This article aims to narrate the various oral complications in individuals suffering from diabetes mellitus. Google search for "diabetes mellitus and oral complications" was done. The search was also carried out for "diabetes mellitus" and its oral complications individually. Diabetes mellitus is a chronic metabolic disorder that is a global epidemic and a common cause of morbidity and mortality in the world today. Currently, there are about 422 million cases of diabetes mellitus worldwide. Diabetic patients can develop different complications in the body such as retinopathy, neuropathy, nephropathy, cardiovascular disease. Complications in the oral cavity have been observed in individuals suffering from diabetes mellitus. A study noted that more than $90 \%$ of diabetic patients suffered from oral complications. Another research has shown a greater prevalence of oral mucosal disorders in patients with diabetes mellitus than non-diabetic population: $45-88 \%$ in patients with type 2 diabetes compared to $38.3-45 \%$ in non-diabetic subjects and $44.7 \%$ in type 1 diabetic individuals compared to $25 \%$ in the non-diabetic population. Oral complications in people with diabetes are periodontal disease, dental caries, oral infections, salivary dysfunction, taste dysfunction, delayed wound healing, tongue abnormalities, halitosis, and lichen planus. The high glucose level in saliva, poor neutrophil function, neuropathy, and small vessel damage contribute to oral complications in individuals with uncontrolled diabetes. Good oral health is imperative for healthy living. Oral complications cause deterioration to the quality of life in diabetic patients. Complications like periodontal disease having a bidirectional relationship with diabetes mellitus even contribute to increased blood glucose levels in people with diabetes. This article intends to promote awareness regarding the oral health of diabetics and to stress the importance of maintaining proper oral hygiene, taking preventive measures, early detection, and appropriate management of oral complications of these patients through a multidisciplinary approach.
\end{abstract}

Keywords: diabetes mellitus, hyperglycemia, oral complications, periodontal disease, salivary dysfunction, dental caries, infection, awareness, multidisciplinary approach

\section{Plain Language Summary}

- Diabetes Mellitus, a global epidemic, is a matter of grave concern worldwide and is a significant cause of morbidity and mortality.

- Oral complications are among the many complications suffered by diabetic patients, including periodontal disease, Dental caries, oral infections, salivary dysfunction, taste dysfunction, delayed wound healing, tongue abnormalities, halitosis, and lichen planus.

- Diabetes Mellitus and oral complications are interrelated, and in conditions like periodontal diseases, the relationship is bidirectional.

- Taste dysfunctions in Diabetes Mellitus often lead to increased sugar consumption, causing further deterioration in glycemic control in diabetic individuals.

- Discomfort experienced by diabetic patients when they suffer from oral complications may discourage oral hygiene due to pain or irritation in the oral cavity. 
- Knowledge regarding oral complications is often inadequate among people with diabetes, and creating awareness is imperative in diabetic individuals about the relationship between diabetes and oral health.

- Diabetic patients need to be educated about these complications, encouraged to maintain oral hygiene, and to pay regular visits to diabetic caregivers and dentists.

- Oral complication prevention, early detection, and appropriate management can only be achieved through a multidisciplinary approach. Dental surgeons and physicians interact effectively to provide the optimum care needed by individuals with Diabetes Mellitus to maintain good oral health free of complications.

\section{Introduction}

Diabetes Mellitus is a non-communicable metabolic disorder that is chronic where there is derangement of insulin action, secretion, or both. A lack of Insulin results in disturbed carbohydrate, protein, and fat metabolism. There are genetic and environmental factors at play for the development of Diabetes Mellitus. The decrease in insulin secretion, reduction in glucose utilization, or increased gluconeogenesis ultimately result in hyperglycemia and harmful changes in different organs. ${ }^{1,2}$

The general categories into which diabetes is classified are as follows: a) Type 1 diabetes b) Type 2 diabetes (c) Diabetes of specific types resulting from other causes like exocrine pancreas disease, chemical or drug-induced diabetes, monogenic diabetes syndrome (d) Gestational Diabetes Mellitus. ${ }^{3}$ In the world at present, 422 million people are suffering from Diabetes Mellitus. Every year there are 1.6 million fatalities linked directly to diabetes. ${ }^{4}$ As per data obtained in studies done throughout the world, an estimation has been made by the International Diabetes Federation that by the year 2045, there will be about 693 million cases of diabetes in the age range of 18-99 years. ${ }^{5}$

Complications related to diabetes are predicted to significantly impact the economy and society as the prevalence of the disease grows. ${ }^{6-10}$ The acute complications of diabetes include ketoacidosis or severe hypoglycemia. Examples of chronic disease complications are retinopathy, neuropathy, cardiovascular disease, and nephropathy. ${ }^{11-14}$

The oral cavity is one of the regions of the body affected by chronic hyperglycemia. Complications arising in the oral cavity due to Diabetes Mellitus result from poor neutrophil function, microangiopathy, neuropathy, collagen synthesis reduction, and collagenase activity reduction. ${ }^{15}$ A study noted that more than $90 \%$ of diabetic patients suffered from oral complications. ${ }^{16}$ Another systemic review has observed a greater prevalence of oral mucosal disorders in patients with Diabetes Mellitus compared to the nondiabetic population: $45-88 \%$ in patients with Type 2 diabetes compared to $38.3-45 \%$ in non-Diabetic subjects and $44.7 \%$ in type 1 diabetic individuals compared to $25 \%$ in the non-Diabetic population. ${ }^{17}$ Tooth decay, gingivitis, oral candidiasis, altered taste, geographic tongue, fissured tongue, dry mouth, the tendency of infection, oral lichen planus, and poor healing of wound are complications of the oral cavity resulting from Diabetes Mellitus. ${ }^{18-23}$

Periodontal disease is among the oral complications of Diabetes Mellitus, which worsens due to hyperglycemia. At the same time, systemic inflammation due to periodontitis deteriorates blood glucose levels in diabetic individuals, thus showing a bidirectional relationship. ${ }^{24}$ Diabetes Mellitus affects the prevalence and incidence of periodontal disease. Formation of deep pockets and loss of attachment is typical in uncontrolled diabetes, and there is a high prevalence rate of periodontitis among diabetic patients of $34 \%-68 \%{ }^{25,26}$ Compared to healthy individuals, the risk of losing alveolar bone is 11 times more in uncontrolled diabetes. ${ }^{18}$

Xerostomia is the dryness of the mouth that has been observed in diabetic patients. A meta-analysis of 32 studies reported that the prevalence of xerostomia was $46.09 \%$ in patients with diabetes, while another study found that $92.5 \%$ of diabetic patients suffered from the reduced salivary flow. ${ }^{27,28}$ This complication eventually results in dysgeusia, dental caries, oral pain, dysphagia, which tends to lower the quality of life of diabetic individuals. ${ }^{28-31}$

Diabetic patients are susceptible to oral infections and delayed wound healing. ${ }^{32,33}$ A high glucose level in the oral cavity and immunocompromised condition in uncontrolled Diabetes Mellitus facilitate oral bacterial infections. ${ }^{18,32}$ Delayed wound healing in Diabetes Mellitus may be attributed to damaged small blood vessels and weakened protection against infection and inflammation. ${ }^{33-35}$

Diabetic patients also suffer from dental caries due to hyposalivation and high salivary glucose level that promotes the growth of bacteria responsible for dental caries. $^{36-38}$ These patients may develop oral complications like taste dysfunction in which diabetic patients' ability to distinguish taste sensations diminishes; ${ }^{39-41}$ Burning Mouth Syndrome is a neuropathic orofacial condition of pain. ${ }^{42}$ Fissured tongue, atrophic glossitis, rhomboid glossitis, benign migratory glossitis are the abnormalities of the tongue suffered by diabetic patients. ${ }^{2,43,44}$ diabetic 
individuals also suffer from Halitosis or bad breath, oral lichen planus, and oral lichenoid reaction (Figure 1). ${ }^{45-49}$

\section{Objectives of the Study}

Individuals with diabetes suffer from many complications. Oral complications affect the quality of life of diabetic patients negatively. ${ }^{50}$ However, knowledge, awareness, and practices regarding this issue are often inadequate among diabetic patients and diabetic caregivers. ${ }^{51-53}$ The objective of this study is to relate the various oral complications of
Diabetes Mellitus and highlight the importance of a multidisciplinary approach through effective interaction between dentists and physicians towards developing awareness among diabetic individuals about oral hygiene checkups, prevention, and management of oral complications.

\section{Materials and Methods}

This narrative review focuses on identifying oral complications in Diabetes Mellitus and the possible pathology leading to these complications. The study was carried out

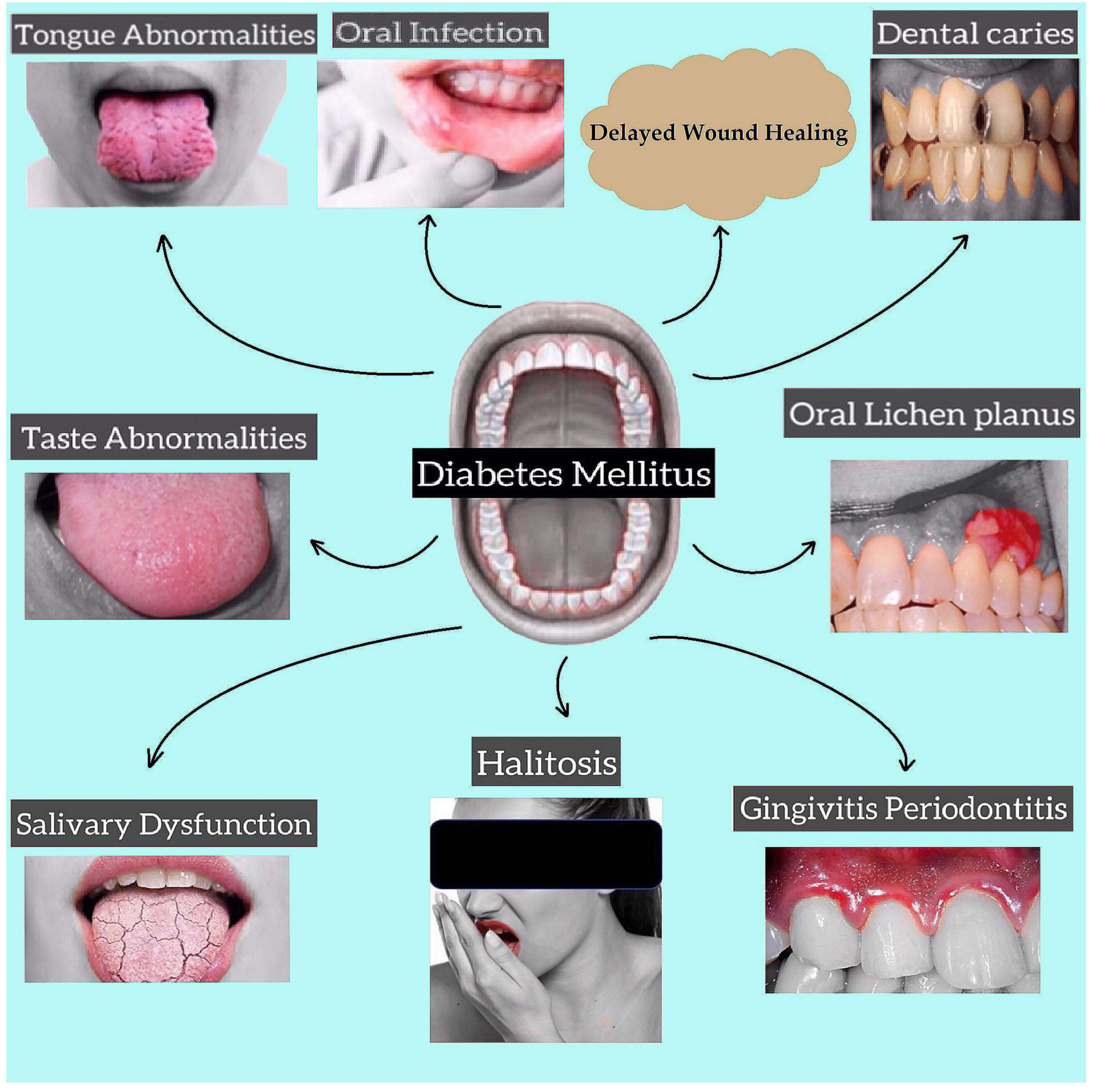

Figure I Complications of oral cavity in diabetes mellitus. 
between March and May 2021. Electronic database search was done using Google search engine, Google Scholar, PubMed, Science Direct. Reference lists in related articles were also searched to obtain more articles on the topics. Keywords used to reach related articles were "Diabetes," "Oral complications," "Oral Manifestations in Diabetes Mellitus," "Dental Caries," "Periodontitis," "Taste alteration," "Xerostomia," "Burning Mouth Syndrome." Articles and literature on those dating before 2000 and articles not available in English were excluded from the study. Relevant articles were hand-searched before being included in the study.

\section{Periodontal Disease in Diabetes Mellitus}

Lang NP and Bartold PM defined periodontal health in 2017 as

A state free from inflammatory periodontal disease that allows an individual to function normally and not suffer any consequences (mental or physical) as a result of past disease.

There are 4 categories of periodontal health, which include a) pristine periodontal health, defined as the total absence of clinical inflammation and physiological immune surveillance on a periodontium with normal support (no attachment or bone loss) (b) clinical periodontal health in which there is an absence or minimum level of clinical inflammation in periodontium having normal support (c) periodontal disease with reduced stability in a periodontium (d) periodontal disease remission/control in a reduced periodontium. ${ }^{54}$

Periodontitis is a chronic inflammatory condition induced by pathogenic biofilm that accumulates on tooth ${ }^{55}$ Gramnegative bacteria Porphyromonas gingivalis, Tannerella forsythia, and Treponema denticola has been suggested to be the primary causative agents for periodontitis. ${ }^{56,57} \mathrm{P}$-gingivalis can trigger inflammatory loss of periodontal bone. ${ }^{58} \mathrm{DNA}$ and lipopolysaccharides from these bacteria cause inflammatory cytokine production by activating nuclear factor $\kappa \beta$ $(\mathrm{NF} \kappa \beta)$ and activating protein-1 pathways. ${ }^{59,60}$ Cytokines cause chemoattraction of neutrophils with an enhancement of ROS production, and NFא $\beta$ and AP-1 activate osteoclast resulting in tissue damage (Figure 2). ${ }^{61-63}$

Increased levels of glucose in crevicular fluid in diabetes may promote the growth of specific microbial species. ${ }^{64}$ Diabetic patients with periodontitis have been noted to have a significantly higher level of local mediators of inflammation like $\mathrm{TNF} \alpha$, IL-1 $\beta$, prostaglandin $\mathrm{E}_{2}$, which causes prolonged osteoclast formation and activity. ${ }^{65-67}$ Interleukin overexpression in diabetes promotes osteoclast genesis and thus prolongs inflammatory response duration. $^{68,69}$ There is also overexpression of RANKL, which interacts with receptors on osteoclast surface and induces osteoclast formation and activity. ${ }^{56,70}$

In Diabetes Mellitus, there is enhanced formation of AGE which interacts with RAGE. This, in turn, promotes osteoclast genesis through increased formation of RANKL receptor activator. ${ }^{71}$ AGE-RAGE interaction also activates $N F \kappa \beta$ and increases the production of inflammatory cytokines. $^{72}$ Neutrophils of diabetic patients release more super-oxides than normal individuals. ${ }^{73}$ Increased ROS plays a significant role in the destruction of periodontal tissue through oxidative stress. ${ }^{64}$ TNF $\alpha$, AGEs, and ROS formation lead to apoptosis of osteoblast in diabetes. ${ }^{74}$ Periodontal infection causes apoptosis of epithelial cells and fibroblast, facilitated in Diabetes Mellitus through a caspase-3-dependent mechanism. ${ }^{75}$ The enhancement and apoptosis that occur in Diabetes Mellitus result in loss of epithelial barrier function and inhibition of repair. ${ }^{76,77}$

People suffering from uncontrolled Diabetes Mellitus are susceptible to periodontal (gum) disease that includes a range of gingiva, ligament, and bone conditions that support teeth. ${ }^{78,79}$ Bacteria in dental plaque initiate local inflammation of the gingiva that, if remain untreated, progress to chronic periodontitis with gingival, ligament, bone loss that form "pockets" in deeper parts of the periodontium. This may lead to tooth loss. ${ }^{80}$.

The outcome of periodontal diseases is affected by hyperglycemia, and at the same time, periodontitis affects glucose levels in the blood adversely. This causes diabetic complications to deteriorate. ${ }^{24}$ An increase in cytokines in saliva and crevicular fluid of gingival, periodontal tissue; oxidative stress with a release of end products of advanced glycation in the hyperglycemic state eventually destroy periodontium due to excessive inflammation. ${ }^{81}$ Diabetes also causes an increase in RANKL expression and impairment of new bone formation in the periodontium. ${ }^{82}$

On the other hand, control of blood glucose in Type 2 diabetic patients deteriorates due to periodontal disease. It induces systemic inflammation through pro-inflammatory cytokine release that causes insulin resistance and bacteremia. ${ }^{83}$ The inflamed periodontium act as a chronic source for bacteria, its products, and mediators of inflammation like TNF $\alpha$, IL 1, and IL 6 that affect glucose metabolism. ${ }^{84}$ The systemic inflammatory cytokines 


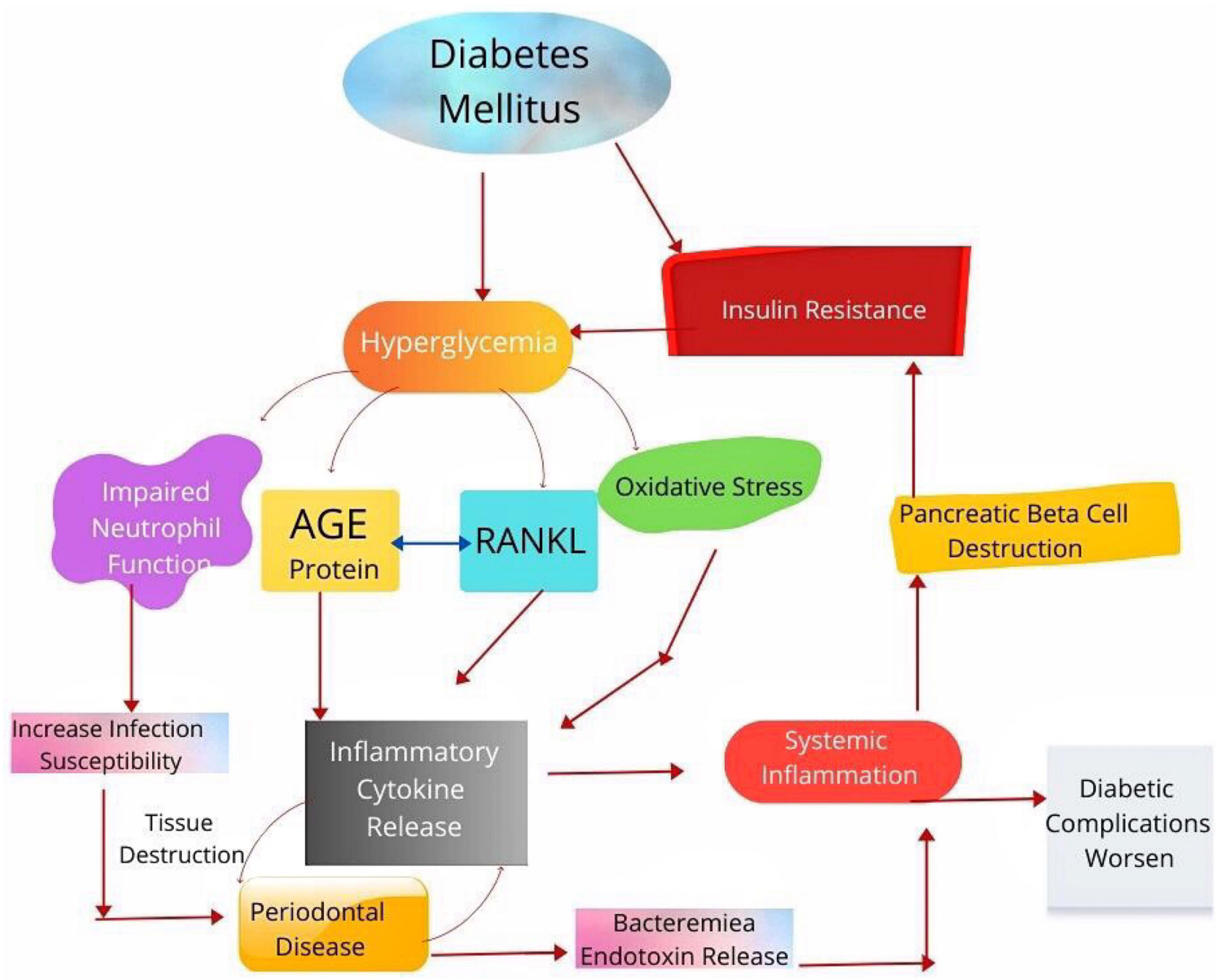

Figure 2 Bidirectional relationship between periodontal disease and diabetes mellitus.

released due to periodontal inflammation also induce insulin resistance by destroying pancreatic $\beta$ cells, insulin action antagonism and alteration of intracellular signaling of insulin through NFk $\beta{ }^{85}$ Improvement of glycemic control was observed in Type 2 diabetic patients who received dental treatment when compared to those diabetic patients who did not obtain dental treatment for periodontal disease. ${ }^{86}$ In a meta-analytic study performed with nine randomized clinical trials, improvement of glycemic control was observed in Diabetes Mellitus patients who received non-surgical treatment of periodontium when compared to those diabetic patients who did not undergo dental treatment for periodontal disease. ${ }^{87}$

\section{Salivary Dysfunction}

The subjective problem of mouth dryness is Xerostomia, and the objective reduction of the flow of saliva is hyposalivation. ${ }^{29}$ There are several systemic disorders related to Xerostomia, including Diabetes Mellitus, inflammatory conditions (rheumatoid arthritis, systemic lupus erythematosus, Sjögren syndrome), metabolic conditions (anemia, bulimia, dehydration), infections (HCV, HIV/ AIDS), neurological disease (Parkinson's disease, depression), and other conditions like sarcoidosis. ${ }^{29,88,89}$ Studies have found a relationship between Diabetes Mellitus (both Type 1 and Type 2) and Xerostomia. ${ }^{28,30,31}$ In patients with uncontrolled diabetes, complications like autonomic neuropathy, changes in the structure of salivary glands, inflammatory change due to hyperglycemia may be a possible cause of the development of Xerostomia. ${ }^{15,90}$ This may lead to a decrease in the flow rate and composition of saliva. ${ }^{91}$ Patients with Xerostomia suffer from glossitis, cervical caries, buccal mucosa dryness, peeled and cracked lips. The individual's quality of life with 
Xerostomia deteriorate as the patient eventually develops dysgeusia, dental caries, periodontal disease, oral pain, and dysphagia. $^{29}$

\section{Infections of the Oral Cavity}

Individuals with Diabetes Mellitus are susceptible to oral cavity infections since these patients are immunocompromised (due to defense function impairment). ${ }^{91,92}$ The bacteria combine with food in teeth forming plaque and result in halitosis, gingivitis, dental caries, and mouth sores. ${ }^{32}$ In the case of oral infection in diabetic individuals, the commonly found bacteria in the oral cavity are $P$. gingivalis, Propionibacterium acnes, Actinomyces israelii, Peptostreptococcus prevotii, Fusobacterium nucleatum, Saccharomyces cerevisiae, Streptococcus sanguis, Prevotella intermedia, and Streptococcus intermedius. The high level of glucose in the saliva of diabetic patients encourages bacterial growth. ${ }^{18}$ Bacterial infections in uncontrolled diabetes may recur and spread from the oral cavity to the rest of the body. Deep neck infections have been observed in diabetic individuals in previous studies. ${ }^{93-97}$

\section{Poor Wound Healing of the Oral Cavity}

There is poor healing of oral wounds in patients having uncontrolled diabetes with associated long-term complications. ${ }^{33}$ Chronic complications of diabetes result from small blood vessel damage. ${ }^{34}$ Lack of proper blood supply hinders nutrient supply to cells that perform an inflammatory function and defend against infective agents. ${ }^{92}$ Inflammation removes dead or damaged tissues, thus allowing healthy tissue to take its place. Temporary spikes in blood sugar cause body defense cells to become paralyzed, resulting in weak protection against infection and inflammatory processes. The tissue healing and regenerative functions are hampered in individuals with uncontrolled diabetes due to hyperglycemia. ${ }^{33,35}$

\section{Dental Caries}

Dental caries is an infectious disease of the teeth in which tooth structure is demineralized due to bacteria, mainly Streptococci mutans, that adheres to the tooth by producing acid from sugar. There are multiple factors like microbial flora: cariogenic, fermentable sugar, environmental factors that trigger dental caries (Figure 3). ${ }^{98}$ Some studies previously carried out have observed a relationship between Diabetes Mellitus and the formation of dental caries. ${ }^{28,99}$ Presence of high glucose level in saliva, decreased saliva flow, alteration of biochemical nature of saliva, salivary buffering effect reduction, bad oral hygiene, cariogenic diet, and existing dental plaque have been associated with dental caries formation in Type 1 Diabetes Mellitus. ${ }^{100}$ Those taking sugar without any restriction are more prone to developing dental caries than those with well-controlled blood glucose levels. ${ }^{43}$ Dental caries occurring in the cementum of teeth become familiar with increasing age, and caries of the radicular part of the tooth have been noted in older patients with Type 2 Diabetes Mellitus. ${ }^{34}$ In a study to observe Type 1 diabetes patients' oral hygiene compared to control, hyposalivation was mentioned as a reason for poor oral hygiene in Type 1 diabetic patients. ${ }^{101}$ A study done in 2017 observed that sugar-free toothpaste in individuals with Diabetes Mellitus decreased salivary glucose level and increased salivary $\mathrm{pH}$ and suggested strict control of blood glucose level to maintain oral hygiene. ${ }^{102}$

Patients with Diabetes Mellitus are especially prone to developing dental caries due to hyposalivation and raised glucose levels in saliva, which may be the outcome of Insulin deficiency. ${ }^{36}$ In people with diabetes, saliva loses protective, buffering as well as cleansing function. ${ }^{37}$ Damage to microvasculature results in changes in the salivary gland basement membrane. Hence, glucose leakage from cells of the duct escalates, leading to a rise in glucose levels in saliva and crevicular space. As a consequence of this change, the activity of fibroblast decreases, resulting in increased plaque formation. Glucose in the saliva is converted by dental plaque into lactic acid, lowering salivary $\mathrm{pH} .{ }^{103,104}$ Aciduric bacterial growth is enhanced in this low $\mathrm{pH}$, and the proliferation of acidogenic bacteria suppresses the oral protective bacteria. There is a shift in the balance of the natural environment, which favors the bacteria responsible for dental caries. This then further decreases $\mathrm{pH}$, and the cycle continues to repeat. ${ }^{37,38}$

\section{Taste Dysfunctions}

Recognition of food taste plays a vital role in a person's food choices, nutrition, life quality and may even be responsible for chronic disease development. ${ }^{105}$ There is a minimum of five modalities of taste sensation that include sweet, sour, bitter, salty, and umami. ${ }^{106}$ The sensation of taste is sensed by receptor cells of taste present in taste buds and papillae in the oral cavity. Following interaction between taste molecules and taste receptors, signals are transmitted utilizing the cranial nerve to the brain. ${ }^{107}$ In case of dysfunction of one or more taste receptors that alter taste perception, may lead to unhealthy eating 


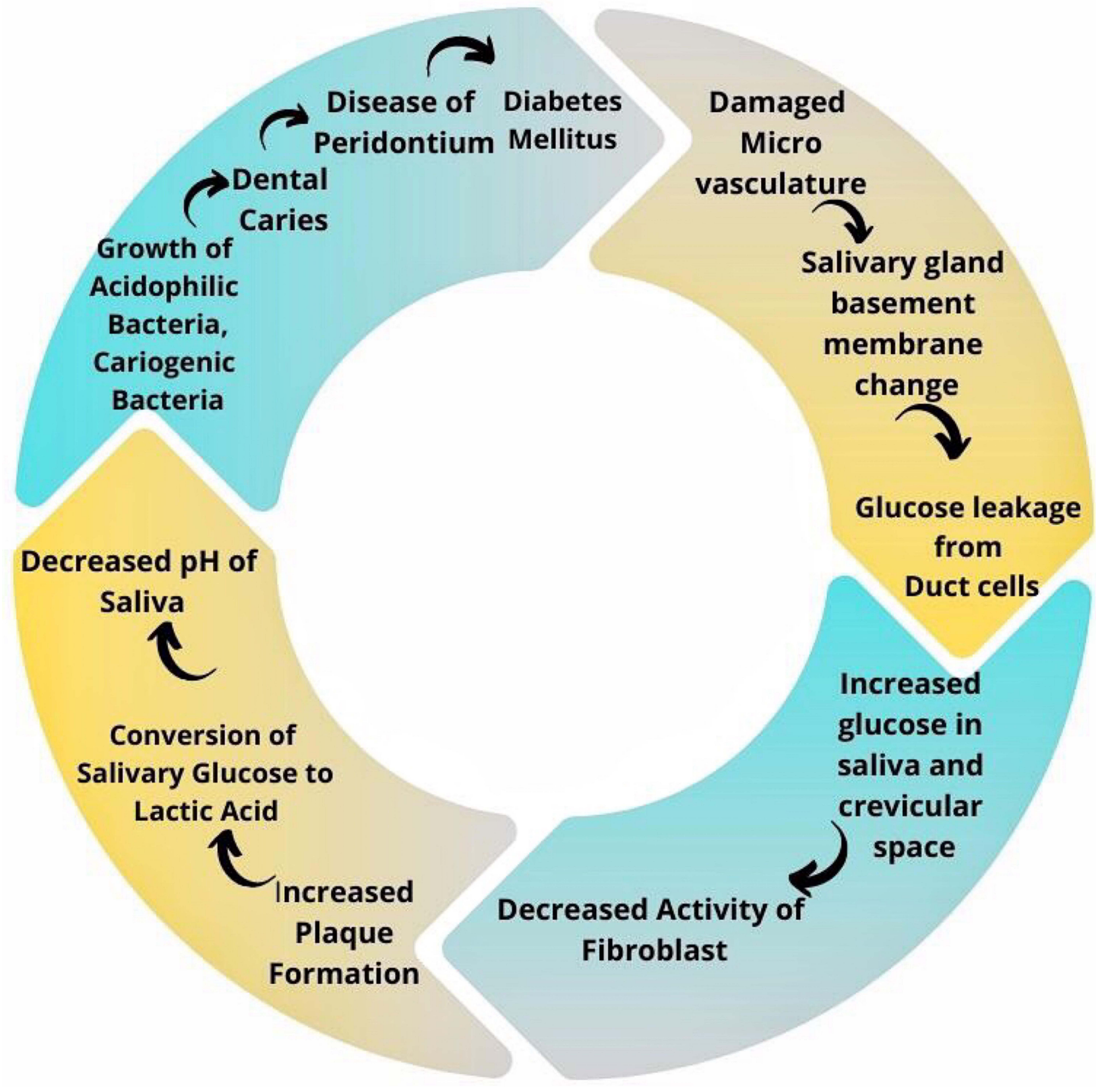

Figure 3 Vicious cycle of diabetes mellitus and formation of dental caries, periodontal disease.

habits. ${ }^{108}$ Studies have shown that distinction and recognition of taste sensation decrease in Diabetes Mellitus (type 1 and type 2). ${ }^{39-41}$ Impairment of taste has also been observed in diabetic individuals without neuropathy. ${ }^{109}$

\section{Burning Mouth Syndrome}

Burning mouth syndrome has been recognized by The International Association for the Study of Pain as a neuropathic orofacial condition of pain with oral mucosal burning pain that commonly affects anterior $2 / 3 \mathrm{rd}$ of the tongue lacking visible pathology of the mucosa. ${ }^{42}$ There is a tingling, burning sensation in the mucosa of the oral cavity without any recognizable cause. ${ }^{110}$ This syndrome has been observed in $18.8 \%$ of type 2 diabetic patients with peripheral neuropathy. ${ }^{111}$ Another study found uncontrolled diabetes and diabetic peripheral neuropathy as strong predictors of Burning mouth syndrome-like symptoms in type 2 diabetic patients. ${ }^{42}$ A study carried out in 2019 to compare the Trigeminal nerve nociceptive function of the oral cavity of patients with diabetic peripheral neuropathy, and healthy 
individuals found increased excitability of trigeminal nerve in diabetic peripheral neuropathy. This can cause hyperesthesia and pain sensation in the oral cavity of diabetic patients with peripheral neuropathy. ${ }^{112}$ Those individuals suffering from long-term burning pain in the mouth have difficulty maintaining oral hygiene, leading to further deterioration in oral health in diabetic patients. ${ }^{43}$

\section{Tongue Abnormalities}

The tongue is an organ composed of muscles having fungiform, filiform, and vallate papillae. It has several functions like taste function utilizing taste buds present on papillae, facilitating speech, and moving food within the oral cavity with bolus formation for swallowing. ${ }^{113}$ Patients with Diabetes Mellitus may suffer from tongue abnormalities. A study in 2019 found the presence of blueish tongue with thick yellow fur in type 2 diabetic individuals and suggested screening of the tongue for early detection of type 2 Diabetes Mellitus. ${ }^{114}$

An abnormality found in diabetic individuals is fissured tongue. This condition is characterized by grooves with depth and size variation on the dorsal tongue surface. Symptoms appear when debris becomes trapped in these fissures. $^{43,115}$ In the study in 2015 , reported fissured tongue was found to have an association with Diabetes Mellitus. ${ }^{115}$ Fissured tongue formation may result from Xerostomia and decreased salivary flow rate. ${ }^{116}$

Atrophic glossitis is a condition of the tongue in which there is the absence of fungiform and filiform papillae on the tongue's dorsal surface, which eventually alters the tongue's appearance and texture, making it smooth and soft. In diabetes mellitus, candida infection in the oral cavity results in the formation of rhomboid glossitis. ${ }^{44}$ This glossitis is marked by an erythematous tongue lesion anterior to the circumvallate papillae. The rhomboidshaped lesion is found on the dorsal surface of the tongue along the midline, which is depapillated, having a shiny, smooth surface, and also referred to as a kissing lesion. ${ }^{117}$

Benign Migratory Glossitis is also found in patients with Diabetes Mellitus. ${ }^{113}$ This condition is benign and marked by redness (erythema), filiform papillae atrophy, lined by a serpiginous, white, hyperkeratosis border. ${ }^{23}$

\section{Halitosis}

Halitosis or bad breath is one of the early diabetes symptoms, a typical ketone smell in people with diabetes. Periodontal disease may also lead to sulfide compound odor. Increased levels of fatty acid and methyl nitrate in blood cause oxidative stress that leads to Halitosis. ${ }^{45}$ A study done in 2015 has found that $23.3 \%$ of the diabetic study recruits suffered from halitosis. ${ }^{118}$

\section{Oral Lichen Planus and Oral Lichenoid Reaction}

Lichen Planus is a chronic inflammatory lesion of the skin. ${ }^{119}$ The lesion is characterized by polygonal, violaceous flat-topped plaques and papules that are pruritic and can appear in different areas of the body, including the oral cavity. The lesion in the oral cavity appears as white raised lines forming a lace-like pattern that is symmetrical and bilateral. ${ }^{120}$ Studies have found oral lichen planus to be present in patients with diabetes. ${ }^{46,47}$ Another mucosarelated change that may have an adverse effect on oral hypoglycemic agents prescribed to diabetic patients is an oral lichenoid reaction. ${ }^{48,49}$ Oral lichen planus is an autoimmune disease in which apoptosis of basal cells of the epithelium of the oral cavity occurs mediated by cytotoxic T cells. ${ }^{121}$ Those suffering from oral lichen planus may complain of discomfort and burning sensation in the mouth that can cause feeding and swallowing difficulty. ${ }^{48}$ Oral lichen planus has malignant potential, so it is vital to diagnose and manage it to prevent oral squamous cell carcinoma development. ${ }^{49}$

\section{Knowledge and Attitude Towards Oral Complications}

Previous studies have shown that diabetic patients were not aware of the bidirectional connection between periodontal disease and Diabetes Mellitus and had limited oral health risk knowledge. ${ }^{122-126}$ In a recent study performed in 2017 on the diabetes care provider's knowledge and practices in oral health care, several obstacles prevented the caregivers from providing effective management. These included lack of guideline/oral health checking instruments, proper referral system, and inadequate knowledge on bidirectional diabetes - oral health relationship. ${ }^{53}$ However, it has been observed from past studies that reception of information about oral health from care providers and better education in this area have shown to result in good knowledge of oral health in diabetic patients. ${ }^{126,127}$ Patients who are informed better regarding diabetes and oral health link take up positive behavior towards oral health. ${ }^{128}$ 


\section{Other Major Complication of Diabetes Mellitus}

Among the major complications of Diabetes Mellitus, Diabetic neuropathies (a heterogeneous group of disorders) are the most prevailing. Diabetic neuropathies like Diffuse neuropathy include distal symmetric polyneuropathy (the most common form of Diabetic peripheral neuropathy) and Autonomic neuropathy; Mononeuropathy; Radiculopathy. ${ }^{129,130}$ The most dominant form of Diabetic neuropathy accounting for about $75 \%$ of the complication is DSPN. ${ }^{131,132}$ Some factors that may increase the risk of developing Diabetic peripheral neuropathy include age, duration of diabetes, diabetic retinopathy. ${ }^{133}$ About half of diabetic patients may suffer from Diabetic neuropathy. ${ }^{134}$ Oxidative stress, inflammation, damage to small blood vessels supplying nerves (vasa nervorum), and neuronal injury and damage due to metabolic disturbance are the possible cause of pathogenesis of diabetic neuropathy. ${ }^{129,135-137}$ In diabetic peripheral neuropathy, there is neuropathic pain burning, shooting, tingling, or lancinating in nature, occurring along with paresthesia worsening during the night. There may be an exaggerated response to stimuli of pain and pain upon contact with, for example, footwear and bedclothes. Such pain may disrupt daily functioning, disability, and negative impact on the quality of life. ${ }^{138-140}$

Cardiovascular complications such as cardiac myopathy and peripheral arterial disease are often diagnosed at the later stage of the disease in diabetic patients. ${ }^{141}$ Advanced atherosclerotic changes have been observed in coronary arteries in both obstructive and nonobstructive coronary stenosis in Type 2 diabetic patients. ${ }^{142,143}$ Complications also include loss of function of regeneration in myocardial muscle and produces acute coronary syndrome. ${ }^{143}$ Response to vasoactive amines is altered that results in adverse cardiac effect. ${ }^{142-144}$ There is a disturbance in genesis and propagation of action potential in cardiac muscle leading to mechanisms of automaticity and re-entry, therefore causing arrhythmias in atria and ventricle. Congestive heart failure in Diabetes Mellitus occurs at a high rate as there is pump failure due to cardiac muscle abnormalities occurring due to inflammation and cardiac fibrosis. ${ }^{144,145}$ Adopting diet and lifestyle changes can help prevent or delay the complications of the cardiovascular system in Type 2 Diabetes Mellitus. ${ }^{146}$
A complication of Diabetes Mellitus that has the probability of leading to blindness is Diabetic Retinopathy. ${ }^{147}$ Risk factors for developing Diabetic Retinopathy include duration of diabetes, hypertension, and poor control of blood glucose level. ${ }^{148}$ Production of free radicals and advanced glycation end products (AGE) and inflammation occurring due to hyperglycemia play an essential role in Diabetic Retinopathy development. ${ }^{149}$ Diabetic Retinopathy is of two types: Non-Proliferative Diabetic Retinopathy (non-threatening to vision) and Proliferative Diabetic Retinopathy (Threatening to vision). ${ }^{147}$ Complications of Proliferative Diabetic Retinopathy like tractional retinal detachment, vitreous hemorrhage, neovascular glaucoma as well as diabetic maculopathy are the causes for vision loss in Diabetic Retinopathy. ${ }^{150}$ Vascular leakage resulting from microangiopathy in diabetic patients causes macular edema and capillary occlusion leading to retinal ischemia and vascular endothelial growth factor elevation. Neovascularization and Proliferative Diabetic Retinopathy thus result from these changes. ${ }^{151,152}$ NonProliferative Diabetic Retinopathy eventually progresses to Proliferative Diabetic Retinopathy, but this progress may be delayed through strict glycemic control in diabetic patients. ${ }^{153}$

One of the major complications of Diabetes Mellitus is Diabetic nephropathy that is found to develop in both Type 1 and Type 2 Diabetes Mellitus. ${ }^{154,155}$ Diabetic nephropathy progresses to chronic kidney disease and eventually leads to end-stage kidney disease. ${ }^{156}$ Upon chronic exposure to high blood glucose levels, podocytes of the glomerular filtration membrane become abnormal. Podocyte loss is one of the earliest morphological changes in the glomerulus, playing an essential role in diabetic nephropathy development. Proteinuria and impairment of renal function are the characteristics of Diabetic Nephropathy. ${ }^{157-159}$ This complication is diagnosed pathologically by findings of renal hypertrophy, thickening of the basement membrane, mesangial substrate increase, nodular lesion, interstitial fibrosis. ${ }^{160-163}$ Changes in renal hemodynamics, ischemia, renin-angiotensin-aldosterone system overactivity, and increased oxidative stress resulting from glucose metabolism and inflammation lead to renal fibrosis in diabetic nephropathy. Control of blood glucose, blood pressure, and lipid; use of Renin-angiotensin-aldosterone system blocker and cessation of smoking can help improve the condition of patients with Diabetic Nephropathy in type 2 Diabetes Mellitus. ${ }^{164}$ 


\section{Limitation of the Study}

The following were some limitations of the study

1. This study is a narrative review, and no systematic review or meta-analysis was not carried out.

2. Search engines that require to be accessed through institutions could not be used.

3. Articles that require to be purchased to be accessed could not be included in the study.

\section{Conclusion}

Diabetes Mellitus has become a significant epidemic in the present world. This metabolic disorder leads to complications, including that of the oral cavity. Oral complications are very much likely to harm the quality of life of the diabetic individual. The individual would suffer hindrance in speech, chewing, swallowing, and have painful sensation in the mouth resulting from these oral complications. In addition, they are prone to oral infections, and taste abnormalities lead them to increase sugar and salt consumption, which further deteriorates their glycemic control and, in turn, degrades the health of the oral cavity. In diabetic patients, mainly when there is insufficient control of blood glucose level, hyperglycemia contributes to several oral complications. At the same time, complications like periodontitis lead to an increase in blood glucose levels and the progress of other complications in the body. Periodontal health is a condition of the inflammation-free periodontium, which allows normal functioning of an individual without any physical or mental consequences due to past disease. The periodontal health is compromised in Diabetes Mellitus, that is, inflammation of periodontium is prolonged and worsened in diabetic individuals suffering from periodontitis. The bidirectional relationship between Periodontitis and Diabetes Mellitus results from the release of inflammatory cytokines like TNF $\alpha$ and interleukins that cause worsening of periodontal disease condition and develop insulin resistance. Systemic inflammatory cytokines and bacterial endotoxins from infected periodontium cause resistance to insulin through pancreatic $\beta$ cell destruction, leading to hyperglycemia. Awareness needs to be built regarding these oral complications since maintaining proper oral hygiene can reduce the incidence and severity of such complications. A multidisciplinary approach that includes dental professionals and physicians is necessary to tackle these complications of the oral cavity in diabetic patients. With regular visits to the dentist and physicians, the oral cavity's blood glucose level and health can remain in check through prevention, early detection, and proper management.

\section{Recommendation}

The interrelated nature of the Diabetes Mellitus and complications of the oral cavity have severe implications for the human body. Awareness needs to be developed regarding the oral complications arising in people with diabetes. Diabetic individuals should be given education about the increased oral health risks, encouraging regular visits to the dentist, and paying attention to oral hygiene. Periodontal screening should be done by dentists and physicians each time a diabetic individual comes for a visit. To halt the appearance of such oral complications, strategies should be in place to assess and manage diabetic individuals at risk. Dentists need to interact effectively with physicians in concerned fields of expertise to provide effective oral care for these diabetic individuals. Guidebooks can be developed by the Diabetic Association, which outlines issues of diabetic care to help dentists recognize better signs and symptoms that require a referral, recommendation for annual screening. This will thus allow for an approach to diabetic care that is proactive beyond their discipline's scope. Also, booklets may be made available for the general population to maintain oral hygiene for diabetic individuals. Physicians and dentists should continue to stress the importance of glycemic control to diabetic patients to maintain a good quality of life.

\section{Consent for Publication}

The author reviewed and approved the final version and has agreed to be accountable for all aspects of the work, including any accuracy or integrity issues.

\section{Acknowledgment}

The authors express their gratitude to Naufela Nafisa Ahmad, Master of Arts in English Language (Linguistics), Jalan Wangsa Delima 7, Wangsa Maju, 53300 Kuala Lumpur, Malaysia, for revising and providing her expert opinion about the quality of the English language of this article. The authors also show gratitude to Faiza Binte Mozammel, Photographer and Editor, 7/16/1 South Mugdapara Dhaka, Bangladesh, for her kind effort and time regarding image development and editing. 


\section{Author Contributions}

All authors made a significant contribution to the work reported, whether that is in the conception, study design, execution, acquisition of data, analysis, and interpretation, or in all these areas; took part in drafting, revising, or critically reviewing the article; gave final approval of the version to be published; have agreed on the journal to which the article has been submitted, and agree to be accountable for all aspects of the work.

\section{Funding}

This paper was not funded.

\section{Disclosure}

The authors declare that they do not have any financial involvement or affiliations with any organization, association, or entity directly or indirectly with the subject matter or materials presented in this article. This also includes honoraria, expert testimony, employment, ownership of stocks or options, patents or grants received or pending, or royalties.

\section{References}

1. Blaslov K, Naranđa FS, Kruljac I, Renar IP. Treatment approach to type 2 diabetes: past, present, and future. World J Diabetes. 2018;9 (12):209-219. doi:10.4239/wjd.v9.i12.209

2. Aynalem SB, Zeleke AJ. Prevalence of diabetes mellitus and its risk factors among individuals aged 15 years and above in Mizan-Aman Town, Southwest Ethiopia, 2016: a Cross-Sectional Study. Int J Endocrinol. 2018;2018:9317987. doi:10.1155/2018/9317987

3. American Diabetes Association. 2. Classification and diagnosis of diabetes: standards of medical care in diabetes-2021. Diabetes Care. 2021;44(Suppl 1):S15-S33. doi:10.2337/dc21-S002

4. World Health Organization. Health topics/diabetes. 20 Avenue Appia, 1211 Geneva 27, Switzerland: WHO Press, World Health Organization; 2021. Available from: https://www.who.int/healthtopics/diabetes\#tab=tab_1. Accessed April 17, 2021.

5. Cho NH, Shaw JE, Karuranga S, et al. IDF diabetes atlas: global estimates of diabetes prevalence for 2017 and projections for 2045 . Diabetes Res Clin Pract. 2018;138:271-281. doi:10.1016/j. diabres.2018.02.023

6. World Health Organization (WHO) Expert Committee. Global report on diabetes. 20 Avenue Appia, 1211 Geneva 27, Switzerland: WHO Press, World Health Organization; 2016. Available from: https://www. who.int/publications/i/item/9789241565257. Accessed April 17, 2021.

7. Sarwar N, Gao P, Seshasai SR, Gobin R, Kaptoge S; Emerging Risk Factors Collaboration. Diabetes mellitus, fasting blood glucose concentration, and risk of vascular disease: a collaborative meta-analysis of 102 prospective studies. Lancet. 2010;375(9733):2215-2222. doi:10.1016/S0140-6736(10)60484-9

8. Dall TM, Yang W, Halder P, et al. The economic burden of elevated blood glucose levels in 2012: diagnosed and undiagnosed diabetes, gestational diabetes mellitus, and prediabetes. Diabetes Care. 2014;37 (12):3172-3179. doi:10.2337/dc14-1036

9. Bhupathiraju SN, Hu FB. Epidemiology of obesity and diabetes and their cardiovascular complications. Circ Res. 2016;118 (11):1723-1735. doi:10.1161/CIRCRESAHA.115.306825
10. Seng JJB, Kwan YH, Lee VSY, et al. Differential health care use, diabetes-related complications, and mortality among five unique classes of patients with type 2 diabetes in Singapore: a latent class analysis of 71,125 patients. Diabetes Care. 2020;43(5):1048-1056. doi:10.2337/dc19-2519

11. Nickerson HD, Dutta S. Diabetic complications: current challenges and opportunities. J Cardiovasc Transl Res. 2012;5 (4):375-379. doi:10.1007/s12265-012-9388-1

12. Maugeri G, Bucolo C, Drago F, et al. Attenuation of high glucose-induced damage in RPE cells through p38 MAPK signaling pathway inhibition. Front Pharmacol. 2021;12:684680. doi:10.3389/ fphar.2021.684680

13. Hap K, Biernat K, Konieczny G. Patients with diabetes complicated by peripheral artery disease: the current state of knowledge on physiotherapy interventions. $J$ Diabetes Res. 2021;2021:5122494. doi:10.1155/2021/5122494

14. Pettus JH, Zhou FL, Shepherd L, et al. Incidences of severe hypoglycemia and diabetic ketoacidosis and prevalence of microvascular complications stratified by age and glycemic control in U.S. adult patients with type 1 diabetes: a Real-World Study. Diabetes Care. 2019;42(12):2220-2227. doi:10.2337/dc19-0830

15. Cicmil A, Govedarica O, Lečić J, Mališ S, Cicmil S, Čakić S. Oral symptoms and mucosal lesions in patients with diabetes mellitus type 2. Balk $J$ Dent Med. 2017;21(1):50-54. doi:10.1515/bjdm-2017-0007

16. Nazir MA, AlGhamdi L, AlKadi M, AlBeajan N, AlRashoudi L, AlHussan M. The burden of diabetes, its oral complications and their prevention and management. Open Access Maced J Med Sci. 2018;6(8):1545-1553. doi:10.3889/oamjms.2018.294

17. González-Serrano J, Serrano J, López-Pintor RM, Paredes VM, Casañas E, Hernández G. Prevalence of oral mucosal disorders in diabetes mellitus patients compared with a control group. J Diabetes Res. 2016;2016:5048967. doi:10.1155/2016/5048967

18. Indurkar MS, Maurya AS, Indurkar S. Oral manifestations of diabetes. Clin Diabetes. 2016;34(1):54-57. doi:10.2337/ diaclin.34.1.54

19. Al-Maskari AY, Al-Maskari MY, Al-Sudairy S. Oral manifestations and complications of diabetes mellitus: a review. Sultan Qaboos Univ Med J. 2011;11(2):179-186.

20. Mauri-Obradors E, Estrugo-Devesa A, Jané-Salas E, Viñas M, López-López J. Oral manifestations of diabetes mellitus. A systematic review. Med Oral Patol Oral Cir Bucal. 2017;22 (5):e586-e594. doi:10.4317/medoral.21655

21. Ship JA. Diabetes and oral health: an overview. J Am Dent Assoc. 2003;134 Spec No:4S-10S. doi:10.14219/jada.archive.2003.0367

22. Trentin MS, Verardi G, Verardi G, Ferreira MDC, da Silva SO, Paranhos LR. Most frequent oral lesions in patients with type 2 diabetes mellitus. J Contemp Dent Pract. 2017;18(2):107-111. doi:10.5005/jp-journals-10024-1999

23. Khan T. Oral manifestations and complications of diabetes mellitus: a review. Int J Med Health Res. 2018;4:50-52. doi:10.22271/ ijmhr

24. Taylor JJ, Preshaw PM, Lalla E. A review of the evidence for pathogenic mechanisms that may link periodontitis and diabetes. J Clin Periodontol. 2013;40(Suppl 14):S113-34. doi:10.1111/ jcpe. 12059

25. Llambés F, Arias-Herrera S, Caffesse R. Relationship between diabetes and periodontal infection. World J Diabetes. 2015;6 (7):927-935. doi:10.4239/wjd.v6.i7.927

26. Bajaj S, Prasad S, Gupta A, Singh VB. Oral manifestations in type-2 diabetes and related complications. Indian $J$ Endocrinol Metab. 2012;16(5):777-779. doi:10.4103/2230-8210.100673

27. Lessa LS, Pires PDS, Ceretta RA, et al. Meta-analysis of prevalence of xerostomia in diabetes mellitus. Int Arch Med. 2015;8 (224):1-13. doi:10.3823/1823 
28. Lima DLF, Carneiro SDRM, Barbosa FTS, Saintrain MVL, Moizan JAH, Doucet J. Salivary flow and xerostomia in older patients with type 2 diabetes mellitus. PLoS One. 2017;12(8): e0180891. doi:10.1371/journal.pone.0180891

29. Mortazavi H, Baharvand M, Movahhedian A, Mohammadi M, Khodadoustan A. Xerostomia due to systemic disease: a review of 20 conditions and mechanisms. Ann Med Health Sci Res. 2014;4(4):503-510. doi:10.4103/2141-9248.139284

30. Navea Aguilera C. The relationship between xerostomia and diabetes mellitus: a little-known complication. Endocrinol Nutr. 2015;62(1):45-46. English, Spanish. doi:10.1016/j. endonu.2014.09.004

31. Hoseini A, Mirzapour A, Bijani A, Shirzad A. Salivary flow rate and xerostomia in patients with type I and II diabetes mellitus. Electron Physician. 2017;9(9):5244-5249. doi:10.19082/5244

32. Mohanty S, Mohanty N, Rath S. Analysis of oral health complications in diabetic patients - a diagnostic perspective. $J$ Oral Res. 2018;7(8):278-281. doi:10.17126/joralres.2018.072

33. Jha R, Kalyani P, Bavishi R. Oral manifestations of diabetes. $J$ Res Med Dent Sci. 2017;2(3):6-8. doi:10.5455/jrmds.2014232

34. Sasaki H, Hirai K, Martins CM, Furusho H, Battaglino R, Hashimoto K. Interrelationship between periapical lesion and systemic metabolic disorders. Curr Pharm Des. 2016;22 (15):2204-2215. doi:10.2174/1381612822666160216145107

35. Spampinato SF, Caruso GI, De Pasquale R, Sortino MA, Merlo S. The treatment of impaired wound healing in diabetes: looking among old drugs. Pharmaceuticals (Basel). 2020;13(4):60. doi: $10.3390 /$ ph13040060

36. Moin M, Malik A. Frequency of dental caries and level of risk among type II diabetic. Dentistry. 2015;5:334-338. doi:10.4172/ 2161-1122.1000334

37. Seetha Lakshmi C, Reddy RC, Asifa N, Prabhu S. Correlation of salivary $\mathrm{pH}$, incidence of dental caries and periodontal status in diabetes mellitus patients: a Cross-Sectional Study. J Clin Diagn Res. 2016;10(3):ZC12-4. doi:10.7860/JCDR/2016/16310.7351

38. Latti BR, Kalburge JV, Birajdar SB, Latti RG. Evaluation of relationship between dental caries, diabetes mellitus and oral microbiota in diabetics. J Oral Maxillofac Pathol. 2018;22 (2):282. doi:10.4103/jomfp.JOMFP_163_16

39. Su N, Ching V, Grushka M. Taste disorders: a review. J Can Dent Assoc. 2013;79:d86.

40. Khera S, Saigal A. Assessment and evaluation of gustatory functions in patients with diabetes mellitus type II: a study. Indian J Endocrinol Metab. 2018;22(2):204-207. doi:10.4103/ijem. IJEM_555_17

41. Wasalathanthri S, Hettiarachchi P, Prathapan S. Sweet taste sensitivity in pre-diabetics, diabetics and normoglycemic controls: a comparative cross-sectional study. BMC Endocr Disord. 2014;14(1):67. doi:10.1186/1472-6823-14-67

42. Renton T. Burning mouth syndrome. Rev Pain. 2011;5(4):127. doi: $10.1177 / 204946371100500403$

43. Ahmad P, Akhtar U, Chaudhry A, Rahid U, Saif S, Asif JA. Repercussions of diabetes mellitus on the oral cavity. Eur J Gen Dent. 2019;8(3):55-62. doi:10.4103/ejgd.ejgd_28_19

44. Erriu M, Pili FM, Cadoni S, Garau V. Diagnosis of lingual atrophic conditions: associations with local and systemic factors. a descriptive review. Open Dent J. 2016;10(1):619-635. doi:10.2174/1874210601610010619

45. Aylıkı BU, Colak H. Halitosis: from diagnosis to management. $J$ Nat Sci Biol Med. 2013;4(1):14-23. doi:10.4103/09769668.107255

46. Atefi N, Majedi M, Peyghambari S, Ghourchian S. Prevalence of diabetes mellitus and impaired fasting blood glucose in patients with lichen planus. Med J Islam Repub Iran. 2012;26(1):22-26.
47. Mozaffari HR, Sharifi R, Sadeghi M. Prevalence of oral lichen planus in diabetes mellitus: a Meta-Analysis Study. Acta Inform Med. 2016;24(6):390-393. doi:10.5455/aim.2016.24.390-393

48. Iqbal MA, Yesmin S, Maaisha F, Ibrahim S, Gotame P. Oral lichen planus and its recent management: a review update. Dent Coll J. 2020;10(2):29-34. doi:10.3329/updcj.v10i2.50179

49. Uma Maheswari T, Chaudhary M. Management of oral lichen planus based on the existing clinical practice guidelines. $J$ Indian Acad Oral Med Radiol. 2020;32(3):284. doi:10.4103/jiaomr. jiaomr_55_20

50. Davis TME, Bruce DG, Curtis BH, Barraclough H, Davis WA. The relationship between intensification of blood glucose-lowering therapies, health status and quality of life in type 2 diabetes: the Fremantle Diabetes Study Phase II. Diabetes Res Clin Pract. 2018;142:294-302. doi:10.1016/j. diabres.2018.05.047

51. Bowyer V, Sutcliffe P, Ireland R, et al. Oral health awareness in adult patients with diabetes: a Questionnaire Study. $\mathrm{Br}$ Dent $J$. 2011;211(6):E12. doi:10.1038/sj.bdj.2011.769

52. Shanmukappa SM, Nadig P, Puttannavar R, Ambareen Z, Gowda TM, Mehta DS. Knowledge, attitude, and awareness among diabetic patients in davangere about the association between diabetes and periodontal disease. J Int Soc Prev Community Dent. 2017;7(6):381-388. doi:10.4103/jisped. JISPCD_390_17

53. Poudel $\bar{P}$, Griffiths R, Wong VW, et al. Perceptions and practices of diabetes educators in providing oral health care: a Qualitative Study. Diabetes Educ. 2018;44(5):454-464. doi:10.1177/ 0145721718796055

54. Lang NP, Bartold PM. Periodontal health. J Periodontol. 2018;89 (Suppl1):S9-S16. doi:10.1002/JPER.16-0517

55. Guthmiller JM, Novak KF. Periodontal diseases. In: Brogden KA, Guthmiller JM, editors. Polymicrobial Diseases. Washington (DC): ASM Press; 2002. Chapter 8. Available from: https://www. ncbi.nlm.nih.gov/books/NBK2496/. Accessed April 17, 2021.

56. Tsaousoglou P, Nietzsche S, Cachovan G, Sculean A, Eick S. Antibacterial activity of moxifloxacin on bacteria associated with periodontitis within a biofilm. $J$ Med Microbiol. 2014;63(Pt 2):284-292. doi:10.1099/jmm.0.065441-0

57. Jünemann S, Prior K, Szczepanowski R, et al. Bacterial community shift in treated periodontitis patients revealed by ion torrent 16S rRNA gene amplicon sequencing. PLoS One. 2012;7(8): e41606. doi:10.1371/journal.pone.0041606

58. Hajishengallis G, Liang S, Payne MA, et al. Low-abundance biofilm species orchestrates inflammatory periodontal disease through the commensal microbiota and complement. Cell Host Microbe. 2011;10(5):497-506. doi:10.1016/j.chom.2011.10.006

59. Mussbacher M, Salzmann M, Brostjan C, et al. Cell type-specific roles of NF- $\mathrm{kB}$ linking inflammation and thrombosis. Front Immunol. 2019;10:85. doi:10.3389/fimmu.2019.00085

60. Iba T, Levy JH. Inflammation and thrombosis: roles of neutrophils, platelets and endothelial cells and their interactions in thrombus formation during sepsis. J Thromb Haemost. 2018;16 (2):231-241. doi:10.1111/jth.13911

61. Dahiya P, Kamal R, Gupta R, Bhardwaj R, Chaudhary K, Kaur S. Reactive oxygen species in periodontitis. J Indian Soc Periodontol. 2013;17(4):411-416. doi:10.4103/0972-124X.118306

62. Mittal M, Siddiqui MR, Tran K, Reddy SP, Malik AB. Reactive oxygen species in inflammation and tissue injury. Antioxid Redox Signal. 2014;20(7):1126-1167. doi:10.1089/ars.2012.5149

63. Yasunari K, Watanabe T, Nakamura M. Reactive oxygen species formation by polymorphonuclear cells and mononuclear cells as a risk factor of cardiovascular diseases. Curr Pharm Biotechnol. 2006;7(2):73-80. doi:10.2174/138920106776597612 
64. Daniel R, Gokulanathan S, Shanmugasundaram N, Lakshmigandhan M, Kavin T. Diabetes and periodontal disease. J Pharm Bioallied Sci. 2012;4(Suppl 2):S280-2. doi:10.4103/09757406.100251

65. Tavares RDCR, Ortigara GB, Tatsch KF, Ferreira CM, Boligon J, Moreira CHC. Association between periodontitis and glycated hemoglobin levels in individuals living in rural Southern Brazil. Clin Oral Investig. 2021. doi:10.1007/s00784-021-03980-y

66. Sima C, Van Dyke TE. Therapeutic targets for management of periodontitis and diabetes. Curr Pharm Des. 2016;22 (15):2216-2237. doi:10.2174/1381612822666160216150338

67. Kayal RA. The role of osteoimmunology in periodontal disease. Biomed Res Int. 2013;2013:639368. doi:10.1155/2013/639368

68. Silva JA, Ferrucci DL, Peroni LA, et al. Sequential IL-23 and IL-17 and increased Mmp8 and Mmp14 expression characterize the progression of an experimental model of periodontal disease in type 1 diabetes. J Cell Physiol. 2012;227(6):2441-2450. doi:10.1002/ jcp. 22979

69. Duarte PM, de Oliveira MC, Tambeli CH, Parada CA, Casati MZ, Nociti FH Jr. Overexpression of interleukin-1beta and interleukin-6 may play an important role in periodontal breakdown in type 2 diabetic patients. J Periodontal Res. 2007;42 (4):377-381. doi:10.1111/j.1600-0765.2006.00961.x

70. Lappin DF, Eapen B, Robertson D, Young J, Hodge PJ. Markers of bone destruction and formation and periodontitis in type 1 diabetes mellitus. J Clin Periodontol. 2009;36(8):634-641. doi:10.1111/j.1600-051X.2009.01440.x

71. Taylor GW, Graves DT, Lamster IB. Periodontal disease as a complication of diabetes mellitus. In: Lamster IB, editor. Diabetes Mellitus and Oral Health: An Interprofessional Approach. Ames: John Wiley \& Sons; 2014:121-142. 9600 Garsington Road, 29 Dzerzhinskogo St. Oxford, OX4 2DQ UK.

72. Kocher T, König J, Borgnakke WS, Pink C, Meisel P. Periodontal complications of hyperglycemia/diabetes mellitus: epidemiologic complexity and clinical challenge. Periodontol 2000. 2018;78 (1):59-97. doi:10.1111/prd.12235

73. Shetty N, Thomas B, Ramesh A. Comparison of neutrophil functions in diabetic and healthy subjects with chronic generalized periodontitis. J Indian Soc Periodontol. 2008;12(2):41-44. doi:10.4103/0972-124X.44089

74. Pacios S, Andriankaja O, Kang J, et al. Bacterial infection increases periodontal bone loss in diabetic rats through enhanced apoptosis. Am J Pathol. 2013;183(6):1928-1935. doi:10.1016/j. ajpath.2013.08.017

75. Kang J, de Brito Bezerra B, Pacios S, et al. Aggregatibacter actinomycetemcomitans infection enhances apoptosis in vivo through a caspase-3-dependent mechanism in experimental periodontitis. Infect Immun. 2012;80(6):2247-2256. doi:10.1128/ IAI.06371-11

76. Graves DT, Liu R, Oates TW. Diabetes-enhanced inflammation and apoptosis: impact on periodontal pathosis. Periodontol 2000. 2007;45(1):128-137. doi:10.1111/j.1600-0757.2007.00219.x

77. Ponugoti B, Dong G, Graves DT. Role of forkhead transcription factors in diabetes-induced oxidative stress. Exp Diabetes Res. 2012;2012:939751. doi:10.1155/2012/939751

78. Zheng M, Wang C, Ali A, Shih YA, Xie Q, Guo C. Prevalence of periodontitis in people clinically diagnosed with diabetes mellitus: a meta-analysis of epidemiologic studies. Acta Diabetol. 2021. doi:10.1007/s00592-021-01738-2

79. Preshaw PM, Alba AL, Herrera D, et al. Periodontitis and diabetes: a two-way relationship. Diabetologia. 2012;55(1):21-31. doi:10.1007/s00125-011-2342-y

80. Könönen E, Gursoy M, Gursoy UK. Periodontitis: a multifaceted disease of tooth-supporting tissues. J Clin Med. 2019;8(8):1135. doi:10.3390/jcm8081135
81. Chapple IL, Genco R; working group 2 of the joint EFP/AAP workshop Diabetes and periodontal diseases: consensus report of the joint EFP/ AAP workshop on periodontitis and systemic diseases. $J$ Periodontol. 2013;84(4Suppl):S106-12. doi:10.1902/jop.2013.1340011

82. Wang X, Wang H, Zhang T, Cai L, Kong C, He J. Current knowledge regarding the interaction between oral bone metabolic disorders and diabetes mellitus. Front Endocrinol (Lausanne). 2020;11:536. doi:10.3389/fendo.2020.00536

83. Jain A, Chawla M, Kumar A, et al. Management of periodontal disease in patients with diabetes- good clinical practice guidelines: a joint statement by Indian society of periodontology and research society for the study of diabetes in India. $J$ Indian Soc Periodontol. 2020;24(6):498-524. doi:10.4103/jisp.jisp_688 20

84. Negrato CA, Tarzia O, Jovanovič L, Chinellato LE. Periodontal disease and diabetes mellitus. J Appl Oral Sci. 2013;21(1):1-12. doi:10.1590/1678-7757201302106

85. Chang P-C, Lim LP. Interrelationships of periodontitis and diabetes: a review of the current literature. J Dent Sci. 2012;7 (3):272-282. doi:10.1016/j.jds.2012.02.002

86. Sundar C, Ramalingam S, Mohan V, Pradeepa R, Ramakrishnan MJ. Periodontal therapy as an adjunctive modality for HbA1c reduction in type-2 diabetic patients. $J$ Edu Health Promot. 2018;7:152. doi:10.4103/jehp.jehp_66_18

87. Li Q, Hao S, Fang J, Xie J, Kong XH, Yang JX. Effect of non-surgical periodontal treatment on glycemic control of patients with diabetes: a meta-analysis of randomized controlled trials. Trials. 2015;16(1):291. doi:10.1186/s13063-015-0810-2

88. López-Pintor RM, Casañas E, González-Serrano J, et al Xerostomia, hyposalivation, and salivary flow in diabetes patients. J Diabetes Res. 2016;2016:4372852. doi:10.1155/2016/4372852

89. Roi A, Rusu LC, Roi CI, et al. Approach for the diagnosis of systemic and oral diseases based on salivary biomolecules. Dis Markers. 2019;2019:8761860. doi:10.1155/2019/8761860

90. Verhulst MJL, Loos BG, Gerdes VEA, Teeuw WJ. Evaluating all potential oral complications of diabetes mellitus. Front Endocrinol (Lausanne). 2019;10:56. doi:10.3389/fendo.2019.00056

91. Al Mubarak S, Robert AA, Baskaradoss JK, et al. The prevalence of oral Candida infections in periodontitis patients with type 2 diabetes mellitus. J Infect Public Health. 2013;6(4):296-301. doi:10.1016/j.jiph.2012.12.007

92. Buranasin P, Mizutani K, Iwasaki K, Pawaputanon Na Mahasarakham C, Kido D, Takeda K. High glucose-induced oxidative stress impairs proliferation and migration of human gingival fibroblasts. PLoS One. 2018;13(8):e0201855. doi:10.1371/journal.pone.0201855

93. Casqueiro J, Casqueiro J, Alves C. Infections in patients with diabetes mellitus: a review of pathogenesis. Indian J Endocrinol Metab. 2012;16(Supp11):S27-S36. doi:10.4103/2230-8210.94253

94. Mustățea P, Bugă C, Doran $\mathrm{H}$, et al. Soft tissue infections in diabetic patients. Chirurgia (Bucur). 2018;113(5):651-667. doi:10.21614/chirurgia.113.5.651

95. Sharma K, Das D, Joshi M, Barman D, Sarma AJ. Deep neck space infections-A study in diabetic population in a tertiary care centre. Indian J Otolaryngol Head Neck Surg. 2018;70(1):22-27. doi:10.1007/s12070-017-1196-0

96. Tibau AV, Grube D. Biological dentistry-whole body health shifting the paradigm in the 21st century. Glob J Otolaryngol. 2020;22 (1):556079. doi:10.19080/GJO.2020.22.556079

97. Akhtar N, Saleem M, Mian FA, Shareef MJ, Hussain F. Head and neck infections; secondary to dental causes; diagnosis and treatment. Prof Med J. 2015;22:787-792.

98. Rathee M, Sapra A. Dental caries. StatPearls [Internet]. Treasure Island (FL): StatPearls Publishing; 2021 [Updated 2021 Mar 12]. Available from: https://www.ncbi.nlm.nih.gov/books/ NBK551699/. Accessed April 17, 2021. 
99. Jeong I-H, Park M-J. The association between diabetes mellitus and community periodontal index. Int J Appl Eng Res. 2017;12 (10):2277-81.

100. Sampaio N, Mello S, Alves C. Dental caries-associated risk factors and type 1 diabetes mellitus. Pediatr Endocrinol Diabetes Metab. 2011;17(3):152-157.

101. Ferizi L, Dragidella F, Spahiu L, Begzati A, Kotori V. The influence of type 1 diabetes mellitus on dental caries and salivary composition. Int J Dent. 2018;2018:5780916. doi:10.1155/2018/5780916

102. Kapadia J, Dodamani A, Baviskar P, Karibasappa GN, Pathak P, Bezalwar A. Effect of sugar-free and regular toothpaste on salivary glucose and ph among type 2 diabetes- a randomized crossover trial. J Clin Diagn Res. 2017;11(7):ZC71-ZC75. doi:10.7860/JCDR/ 2017/25580.10250

103. Abikshyeet P, Ramesh V, Oza N. Glucose estimation in the salivary secretion of diabetes mellitus patients. Diabetes Metab Syndr Obes. 2012;5:149-154. doi:10.2147/DMSO.S32112

104. Hariharavel V, Rao AP, Venugopal RN, Peter J. Diabetes, diet, and dental caries. Int J Diabetes Dev Ctries. 2017;37(1):94. doi:10.1007/s13410-015-0400-6

105. Puputti S, Hoppu U, Sandell M. Taste sensitivity is associated with food consumption behavior but not with recalled pleasantness. Foods. 2019;8(10):444. doi:10.3390/foods 8100444

106. Kinnamon SC. Taste receptor signaling - from tongues to lungs. Acta Physiol (Oxf). 2012;204(2):158-168. doi:10.1111/j.17481716.2011.02308.x

107. Puputti S, Hoppu U, Sandell M, Aisala H. Factors explaining individual differences in taste sensitivity and taste modality recognition among Finnish adults. J Sens Stud. 2019;34(4): e12506. doi:10.1111/joss.12506

108. Pugnaloni S, Alia S, Mancini M, et al. A study on the relationship between type 2 diabetes and taste function in patients with good glycemic control. Nutrients. 2020;12(4):1112. doi:10.3390/ nu12041112

109. Bhandare NN, Keny MS, Nevrekar RP, Bhandare PN. Diabetic tongue - could it be a diagnostic criterion? J Fam Med Prim Care. 2014;3(3):290-291. doi:10.4103/2249-4863.141654

110. Kamala KA, Sankethguddad S, Sujith SG, Tantradi P. Burning mouth syndrome. Indian J Palliat Care. 2016;22(1):74-79. doi:10.4103/0973-1075.173942

111. Nada A, Abdel Moneim W, Fakhr M, El Sawy S. Prevalence of burning mouth syndrome in a sample of Egyptian patients with diabetic neuropathy: a Cross-Sectional Hospital-Based Study. Adv Dent J. 2020;2(2):34-42. doi:10.21608/adjc.2020.23213.1050

112. Costa YM, Karlsson P, Bonjardim LR, et al. Trigeminal nociceptive function and oral somatosensory functional and structural assessment in patients with diabetic peripheral neuropathy. Sci Rep. 2019;9(1):169. doi:10.1038/s41598-018-37041-4

113. Dotiwala AK, Samra NS. Anatomy, head and neck, tongue. StatPearls [Internet]. Treasure Island (FL): StatPearls Publishing; 2021 [Updated 2020 Aug 22]. Available from: https://www.ncbi. nlm.nih.gov/books/NBK507782/. Accessed April 17, 2021.

114. Hsu PC, Wu HK, Huang YC, et al. The tongue features associated with type 2 diabetes mellitus. Medicine (Baltimore). 2019;98(19): e15567. doi:10.1097/MD.0000000000015567

115. Sudarshan R, Sree Vijayabala G, Samata Y, Ravikiran A. Newer classification system for fissured tongue: an epidemiological approach. J Trop Med. 2015;2015:262079. doi:10.1155/2015/ 262079

116. Villa A, Connell CL, Abati S. Diagnosis and management of xerostomia and hyposalivation. Ther Clin Risk Manag. 2014;11:45-51. doi:10.2147/TCRM.S76282

117. Bihari M, Srivastava R, Jyoti B, Mehrota V, Gupta M, Pradhan S. Median rhomboid glossitis with palatal kissing lesion-a case report. Bang J Dent Res Edu. 2014;4(2):94-97. doi:10.3329/ bjdre.v4i2.20273
118. Ravindran R, Deepa MG, Sruthi AK, et al. Evaluation of oral health in type II diabetes mellitus patients. Oral Maxillofac Path J. 2015;6(1):525-531. doi:10.5005/10037-1030

119. Khandelwal V, Nayak PA, Nayak UA, Gupta A. Oral lichen planus in a young Indian child. BMJ Case Rep. 2013;2013 (aug13 2):bcr2013010516. doi:10.1136/bcr-2013-010516

120. Weston G, Payette M. Update on lichen planus and its clinical variants. Int $J$ Womens Dermatol. 2015;1(3):140-149. doi:10.1016/j.ijwd.2015.04.001

121. Gupta S, Jawanda MK. Oral lichen planus: an update on etiology, pathogenesis, clinical presentation, diagnosis, and management. Indian J Dermatol. 2015;60(3):222-229. doi:10.4103/00195154.156315

122. Sahril N, Aris T, Mohd Asari AS, et al. Oral health-seeking behavior among Malaysians with type II diabetes. J Public Health Aspects. 2014;1(1):1. doi:10.7243/2055-7205-1-1

123. Arunkumar S, Amur S, Sambrani U, Burde KM. Survey on awareness and knowledge about the effect of diabetes mellitus on systemic and oral health in patients visiting general medicine outpatient department in dental hospital. J Krishna Inst Med Sci. 2015;4(2):100-106.

124. Badiah B. A preliminary survey on awareness of periodontal risk and oral health practices among diabetic patients in hospital Kuala Lumpur. Malaysian Dent J. 2012;34(1):1-7.

125. Aggarwal A, Panat SR. Oral health behavior and $\mathrm{HbA} 1 \mathrm{c}$ in Indian adults with type 2 diabetes. J Oral Sci. 2012;54(4):293-301. doi:10.2334/josnusd.54.293

126. Bahammam MA. Periodontal health and diabetes awareness among Saudi diabetes patients. Patient Prefer Adherence. 2015;9:225-233. doi:10.2147/PPA.S79543

127. Al Amassi BY, Al Dakheel RS. Oral hygiene practice of adult diabetic patients and their awareness about oral health problems related to diabetes. J Dent Oral Hyg. 2017;9(2):8-14. doi:10.5897/JDOH2017.0219

128. Poudel P, Griffiths R, Wong VW, et al. Oral health knowledge, attitudes and care practices of people with diabetes: a systematic review. BMC Public Health. 2018;18(1):577. doi:10.1186/ s12889-018-5485-7

129. Busui RP, Boulton AJM, Feldman EL, et al. Diabetic neuropathy: a position statement by the American Diabetes Association. Diabetes Care. 2017;40(1):136-154. doi:10.2337/dc16-2042

130. Weng YC, Tsai SS, Lyu RK, et al. Diabetic distal symmetrical polyneuropathy: correlation of clinical, laboratory, and electrophysiologic studies in patients with type 2 diabetes mellitus. $J$ Diabetes Res. 2020;2020:6356459. doi:10.1155/2020/ 6356459

131. Albers JW, Pop-Busui R. Diabetic neuropathy: mechanisms, emerging treatments, and subtypes. Curr Neurol Neurosci Rep. 2014;14(8):473. doi:10.1007/s11910-014-0473-5

132. Dyck PJ, Albers JW, Andersen H, et al.; Toronto Expert Panel on Diabetic Neuropathy. Diabetic polyneuropathies: update on research definition, diagnostic criteria, and estimation of severity. Diabetes Metab Res Rev. 2011;27(7):620-628. doi:10.1002/dmrr.1226

133. Liu X, Xu Y, An M, Zeng Q. The risk factors for diabetic peripheral neuropathy: a meta-analysis. PLoS One. 2019;14(2): e0212574. doi:10.1371/journal.pone.0212574

134. Alam U, Riley DR, Jugdey RS, et al. Diabetic neuropathy and gait: a review. Diabetes Ther. 2017;8(6):1253-1264. doi:10.1007/ s13300-017-0295-y

135. Islam MR, Rahman T, Habib R, et al. Electrophysiological patterns of diabetic polyneuropathy: experience from a tertiary care hospital of Bangladesh. BIRDEM Med J. 2017;7(2):114-120. doi:10.3329/birdem.v7i2.32448

136. Javed S, Petropoulos IN, Alam U, Malik RA. Treatment of painful diabetic neuropathy. Ther Adv Chronic Dis. 2015;6(1):15-28. doi:10.1177/2040622314552071 
137. Arpith MN, Narayan V. Prevalence and determinants of peripheral neuropathy in patients with type 2 diabetes mellitus. Indian J Clin Anat Physiol. 2021;8(1):57-59. doi:10.1823/j.ijcap.2021.013

138. Vileikyte L, Leventhal H, Gonzalez JS, et al. Diabetic peripheral neuropathy and depressive symptoms: the association revisited. Diabetes Care. 2005;28(10):2378-2383. doi:10.2337/diacare.28.10.2378

139. Schreiber AK, Nones CF, Reis RC, Chichorro JG, Cunha JM. Diabetic neuropathic pain: physiopathology and treatment. World J Diabetes. 2015;6(3):432-444. doi:10.4239/wjd.v6.i3.432

140. Vinik A, Casellini C, Nevoret ML. Diabetic neuropathies. In: Feingold KR, Anawalt B, Boyce A, et al. editors. Endotext [Internet]. South Dartmouth (MA): MDText.com, Inc.; 2018. Available from: https://www.ncbi.nlm.nih.gov/books/ NBK279175/. Accessed April 17, 2021

141. Zhou B, Lu Y, Hajifathalian K; NCD Risk Factor Collaboration (NCD-RisC). Worldwide trends in diabetes since 1980: a pooled analysis of 751 population-based studies with 4.4 million participants. Lancet. 2016;387(10027):1513-1530. doi:10.1016/ S0140-6736(16)00618-8

142. Sardu C, Paolisso P, Sacra C, et al. Cardiac resynchronization therapy with a defibrillator (CRTd) in failing heart patients with type 2 diabetes mellitus and treated by glucagon-like peptide 1 receptor agonists (GLP-1 RA) therapy vs. conventional hypoglycemic drugs: arrhythmic burden, hospitalizations for heart failure, and CRTd responders rate. Cardiovasc Diabetol. 2018;17(1):137. doi:10.1186/s12933-018-0778-9

143. Sardu C, Barbieri M, Santamaria M, et al. Multipolar pacing by cardiac resynchronization therapy with a defibrillators treatment in type 2 diabetes mellitus failing heart patients: impact on responders rate, and clinical outcomes. Cardiovasc Diabetol. 2017;16(1):75. doi:10.1186/s12933-017-0554-2

144. Sardu C, Barbieri M, Balestrieri ML, et al. Thrombus aspiration in hyperglycemic ST-elevation myocardial infarction (STEMI) patients: clinical outcomes at 1-year follow-up. Cardiovasc Diabetol. 2018;17(1):152. doi:10.1186/s12933-018-0795-8

145. Sardu C, D’Onofrio N, Mauro C, Balestrieri ML, Marfella R. Thrombus aspiration in hyperglycemic patients with high inflammation levels in coronary thrombus. J Am Coll Cardiol. 2019;73 (4):530-531. doi:10.1016/j.jacc.2018.10.074

146. Galaviz KI, Narayan KMV, Lobelo F, Weber MB. Lifestyle and the prevention of type 2 diabetes: a status report. Am J Lifestyle Med. 2015;12(1):4-20. doi:10.1177/1559827615619159

147. Vieira-Potter VJ, Karamichos D, Lee DJ. Ocular complications of diabetes and therapeutic approaches. Biomed Res Int. 2016;2016:3801570. doi:10.1155/2016/3801570

148. Simó-Servat O, Hernández C, Simó R. Diabetic retinopathy in the context of patients with diabetes. Ophthalmic Res. 2019;62 (4):211-217. doi:10.1159/000499541

149. Simó R, Hernández C; European Consortium for the Early Treatment of Diabetic Retinopathy (EUROCONDOR). Neurodegeneration in the diabetic eye: new insights and therapeutic perspectives. Trends Endocrinol Metab. 2014;25(1):23-33. doi:10.1016/j.tem.2013.09.005
150. Nentwich MM, Ulbig MW. Diabetic retinopathy - ocular complications of diabetes mellitus. World J Diabetes. 2015;6 (3):489-499. doi:10.4239/wjd.v6.i3.489

151. Barot M, Gokulgandhi MR, Patel S, Mitra AK. Microvascular complications and diabetic retinopathy: recent advances and future implications. Future Med Chem. 2013;5(3):301-314. doi:10.4155/fmc. 12.206

152. Fong DS, Aiello LP, Ferris FL 3rd, Klein R. Diabetic retinopathy. Diabetes Care. 2004;27(10):2540-2553. doi:10.2337/ diacare.27.10.2540

153. Simó R, Hernández C. Advances in the medical treatment of diabetic retinopathy. Diabetes Care. 2009;32(8):1556-1562. doi:10.2337/dc09-0565

154. Kim K-S, Lee J-S, Park J-H, et al. Identification of novel biomarker for early detection of diabetic nephropathy. Biomedicines. 2021;9(5):457. doi:10.3390/biomedicines9050457

155. Rigalleau V, Lasseur C, Raffaitin C, et al. Normoalbuminuric renal-insufficient diabetic patients: a lower-risk group. Diabetes Care. 2007;30(8):2034-2039. doi:10.2337/dc07-0140

156. Alicic RZ, Rooney MT, Tuttle KR. Diabetic kidney disease: challenges, progress, and possibilities. Clin J Am Soc Nephrol. 2017;12(12):2032-2045. doi:10.2215/CJN.11491116

157. Fakhruddin S, Alanazi W, Jackson KE. Diabetes-induced reactive oxygen species: mechanism of their generation and role in renal injury. J Diabetes Res. 2017;2017:8379327. doi:10.1155/2017/ 8379327

158. Cao Z, Cooper ME. Pathogenesis of diabetic nephropathy. $J$ Diabetes Investig. 2011;2(4):243-247. doi:10.1111/j.20401124.2011.00131.x

159. Park TS. How much glycemic control is needed to prevent progression of diabetic nephropathy? J Diabetes Investig. 2012;3 (5):411-412. doi:10.1111/j.2040-1124.2012.00225.x

160. Williams ME, Garg R. Glycemic management in ESRD and earlier stages of CKD. Am J Kidney Dis. 2014;63(2 Suppl 2):S2238. doi:10.1053/j.ajkd.2013.10.049

161. DeFronzo RA, Reeves WB, Awad AS. Pathophysiology of diabetic kidney disease: impact of SGLT2 inhibitors. Nat Rev Nephrol. 2021;17(5):319-334. doi:10.1038/s41581-021-00393-8

162. Phillips AO, Baboolal K, Riley S, et al. Association of prolonged hyperglycemia with glomerular hypertrophy and renal basement membrane thickening in the Goto Kakizaki model of non-insulindependent diabetes mellitus. Am J Kidney Dis. 2001;37 (2):400-410. doi:10.1053/ajkd.2001.21322

163. Tervaert TW, Mooyaart AL, Amann K, et al.; Renal Pathology Society. Pathologic classification of diabetic nephropathy. $\mathrm{J} \mathrm{Am}$ Soc Nephrol. 2010;21(4):556-563. doi:10.1681/ASN.2010010010

164. Lin YC, Chang YH, Yang SY, Wu KD, Chu TS. Update of pathophysiology and management of diabetic kidney disease. $J$ Formos Med Assoc. 2018;117(8):662-675. doi:10.1016/j. jfma.2018.02.007

Diabetes, Metabolic Syndrome and Obesity: Targets and Therapy

Dovepress

\section{Publish your work in this journal}

Diabetes, Metabolic Syndrome and Obesity: Targets and Therapy is an international, peer-reviewed open-access journal committed to the rapid publication of the latest laboratory and clinical findings in the fields of diabetes, metabolic syndrome and obesity research. Original research, review, case reports, hypothesis formation, expert opinion and commentaries are all considered for publication. The manuscript management system is completely online and includes a very quick and fair peer-review system, which is all easy to use. Visit http://www.dovepress.com/testimonials.php to read real quotes from published authors. 